\title{
ENHANCING ANTIOXIDANT ACTIVITIES OF LIVER PÂTÉ BY BOLETUS EDULIS SUPPLEMENTATION
}

CRISTINA SOLER-RIVAS*, ANA CRISTINA RAMÍREZ-ANGUIANO, GUILLERMO REGLERO AND SUSANA SANTOYO

Unit of Food Science and Technology. Faculty of Sciences. Universidad Autónoma de Madrid (UAM). Spain.

Running title: Antioxidant activities of pâté with added B. edulis

Corresponding author footnote: ${ }^{*}$ Cristina Soler-Rivas. Universidad Autónoma de Madrid (UAM). Edificio de Ciencias. Sección departamental Ciencias de la Alimentación. Modulo C-XVI (502.1). Ctra de Colmenar, km 15. 28049 Madrid. Spain. Cristina.soler@uam.es. Tel: +34 9149728 60. Fax: +34 914978255. 
The antioxidant properties of liver pâtés might be enhanced by adding specific

bioactive ingredients such as Boletus edulis mushrooms. Water- and methanol-

soluble fractions of supplemented pâtés showed higher ABTS and DPPH

scavenging activities than control samples. B. edulis supplementation resulted

in lower $E C_{50}$ but only up to $5 \%(\mathrm{w} / \mathrm{w})$. The high antioxidant activity observed in supplemented pâtés was stable during 30 storage days and decreased after 60 days but still it was higher than control pâtés and did not influence lipid oxidation. Addition of dried water or methanol preparations extracted from the mushroom did not improve the antioxidant activity observed when the complete fruiting body was utilized. Ergosterol- related compounds and ergotioneine were involved, but they were not exclusively responsible of the high antioxidant activity observed, phenolic compounds might be involved too.

\section{PRACTICAL APPLICATION}

Antioxidants are thought to exert a potential protective effect against free radical damage preventing cardiovascular diseases (CVD) and tumour formation by inhibiting oxidative reactions on DNA, lipids, etc. Traditional liver pâtés are a good source of bioavailable iron but they are also rich on saturated fatty acids and cholesterol. The frequent consumption of the latter compounds increases the risk of CVD. Moreover, the industrial manufactures usually add synthetic antioxidants to inhibit pâtés lipid oxidation, since their iron content might act as catalyst and accelerate lipid oxidation reactions. Edible fungi are a good source of natural antioxidants and fungal flavours, textures and colours are similar to animal products. Therefore, B. edulis fruiting bodies could be added at low 
46 concentrations $(2.5-1 \% \mathrm{w} / \mathrm{w})$ to liver pâté to design a new functional pâté with

47 higher antioxidant activities without the need of synthetic antioxidants to prevent 48 lipid oxidation up to 30 storage days.

49

50 Keywords:

51 Mushroom, DPPH, ABTS, TBARS, ergosterol, ergothioneine, TLC, functional 52 ingredients 
Liver pâtés, spreading pastes commonly consumed worldwide, are generally considered as an added value product with high sensory qualities and nutritional value because of their iron content but with a high amount of fat (approx. 35\%) (Estevez et al. 2007).

During the pâté preparation, chopping and mincing of liver and other fatty ingredients facilitate oxygen interaction with the paste matrix. Later on, the pasteurization procedure increases the temperature and the high iron levels catalyze oxidative reactions on the free fatty acids provoking hydroperoxides and other degradation products (Kanner et al. 1991).

Traditionally, industrial manufactures usually added synthetic antioxidants such as butylated hydroxyanisole (BHA), butylated hydroxytoluene (BHT), propyl, octyl, and dodecyl gallates etc. to inhibit pâté lipid oxidation (Pinho et al. 2000). Actually, other alternatives are being investigated such as the use of sage and rosemary essential oils (Estevez et al. 2007). However, edible fungi are also a good source of natural antioxidants and fungal flavours, textures and colours are more similar to animal products than plant extracts (Tsai et al. 2007).

Boletus edulis is a widely consumed mushroom with appreciated sensory characteristics and nutritional value. Boletus sp. contains high levels of carbohydrates including dietary fibres and proteins and very low fat content (Manzi et al. 2001; Ouzouni and Riganakos 2007). They are a good source of vitamins and minerals (Mattila et al. 2001) particularly, a high Vitamin $D_{2}$ (Mattila et al. 2002; Teichmann et al. 2007) and selenium contents (8.7 - $32 \mu \mathrm{g} / \mathrm{kg} \mathrm{DM})$ (Falandysz 2003) and a wide range of nutraceuticals (Wasser 2002; Zheng et al. 2007). These basidiomycetes contain bioactive compounds with high 
antioxidant (Ramirez-Anguiano et al. 2007; Tsai et al. 2007; Sarikurkcu et al. 2008), antimicrobial (Lee et al. 1999; Santoyo et al. 2009), antitumor and immunomodulating properties (Wasser 2002; Zhen et al. 2007).

There is a new trend in the market to functionalize food by adding specific ingredients of natural origin, which might not only avoid the food spoilage but improve consumer's health. Usually, to reach that health beneficial effect, the natural compounds have to be extracted and concentrated using more or less complicated technologies to prepare an active concentrate (Kitzberger et al. 2007). The objective of this work is to demonstrate that the antioxidant status of a liver pâte might be improved just by promoting new " recipes" with specific combination of food ingredients, for instance, by adding powdered mushroom fruiting bodies directly to pâtés. Liver pâtés - if consumed in large quantities could increase the risk of cardiovascular diseases (CVD) because of its high saturated fat and cholesterol levels. Moreover, such a high amount of fat might be easily oxidized (in the absence of antioxidant compounds) during the pâté preparation and/or during storage. In this work Boletus edulis fruiting bodies were added to liver pâtés to study whether they were able to inhibit lipid oxidation and enhance the antioxidant properties of the food matrix. The effect of pâté processing and storage on these properties was also investigated. Therefore, the ABTS and DPPH scavenging activities and TBARS values of traditional and supplemented pâtés were compared. A preliminary study using TLC was carried out to visualize the antioxidants potentially responsible of the observed activities. 
Materials and reagents

The mushroom used in this investigation was a wild strain of Boletus edulis

107 (Fries/Bull). Fresh mushroom fruit bodies, Iberian pork bacon, beef liver, pepper, salt, powered garlic and white wine were purchased at a local

109 supermarket. 2,2'-Azino-bis(3-ethylbenzothiazoline-6-sulfonic acid (ABTS $\left.{ }^{\bullet+}\right)$, 2,2-diphenyl-1picrylhydrazyl (DPPH$\left.{ }^{\bullet}\right), 2-$ Thiobarbituric acid, and 1,1,3,3 tetraethoxypropane

112 (TEP) were purchased from Sigma-Aldrich Chemie GmbH (Steinheim, were obtained from Panreac Quimica SA 17 (Barcelona, Spain).

\section{Samples preparation}

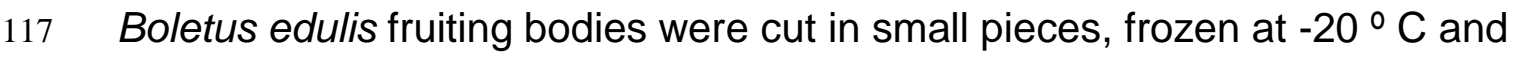
lyophilized (Unitop 400 SL, Virtis, Gardiner, NY, USA). Dehydrated material was homogenized in a mill (JR MF10basic IKA Laburtechnick, Germany) and sieved (Orto Alresa, Spain) until particle size was smaller than $0.3 \mathrm{~mm}$. The resulting powder was stored at $-20^{\circ} \mathrm{C}$ and marked as complete mushroom powder (BC) or submitted to extraction using water and methanol as solvents.

123 Boletus edulis water fractions (BWF) were prepared by adding $500 \mathrm{~mL}$ distilled water to $10 \mathrm{~g}$ mushroom powder. The mixture was stirred and submitted to centrifugation at $5^{\circ} \mathrm{C}, 3500 \mathrm{rpm}$ during $15 \mathrm{~min}$. Supernatant was collected, stored at $-20 \stackrel{\circ}{ } \mathrm{C}$ and lyophilized. 
127 Boletus edulis methanol fractions (BMF) were prepared by adding $10 \mathrm{~mL}$ methanol to $1 \mathrm{~g}$ mushroom powder and shaking in a Vortex during $2 \mathrm{~min}$. The mixture was submitted to centrifugation at $12000 \mathrm{rpm}$ during $2 \mathrm{~min}$. Supernatant was dried in a vacuum concentrator (SpeedVac plus, Savant Instruments Inc. Holbrock, NY, USA).

Liver pâtés were prepared following a domestic recipe. Beef liver (166 g) was cut in pieces, mixed with $333 \mathrm{~g}$ bacon pieces and ground in a mixer (Ufesa, 600 W, Spain) until a fine paste was obtained. Pepper (0.42 g), salt (3.33 g), powdered garlic $(0.333 \mathrm{~g})$ and $25 \mathrm{~mL}$ white wine were added and mixed with the paste. In pâtés supplemented with $B$. edulis preparations, different concentrations were added $(\mathrm{BC}=1,2.5,5$ and $7.5 \%, \mathrm{BWF}=0.25$ and $1.25 \%$ and $\mathrm{BMF}=0.12$ and $0.62 \% \mathrm{w} / \mathrm{w}$ ) together with these condiments. Crude pâté $(90 \mathrm{~g})$ was placed in jars $(200 \mathrm{~mL})$ sterilized in an autoclave at $121^{\circ} \mathrm{C}$ for 20 $\min$ and for storage experiments a few jars were maintained at $4{ }^{\circ} \mathrm{C}$ in darkness up to 60 days.

\section{DPPH` scavenging capacity}

For $\mathrm{DPPH}^{\bullet}$ assays, the antioxidant compounds were extracted following two procedures. In the first procedure, liver pâtés $(5 \mathrm{~g})$ were mixed twice with $10 \mathrm{~mL}$ hexane, stirred for 4 min to remove fat samples before methanol extraction. Hexane phase was removed using vacuum. Defatted paste was mixed twice with $10 \mathrm{~mL}$ (x2) methanol and stirred for $4 \mathrm{~min}$. Supernatants were pooled together and evaporated until dryness in a rotary evaporator (Laborota 4000efficient. Heidolph Instruments, Germany). Dry extracts were dissolved in methanol for the analysis. In the second procedure, liver pâtés $(5 \mathrm{~g})$ were 
152 directly submitted to methanol extraction without fat removal, concentrated and 153 treated as previous samples.

154 Scavenging effect on $\mathrm{DPPH}^{\bullet}$ free radical was monitorized according to

155 Ramirez-Anguiano et al. (2007). The $\mathrm{EC}_{50}$ was defined as the concentration of antioxidant power.

\section{ABTS $^{*+}$ scavenging capacity} dry extract able to scavenge half of the radical and it was calculated in order to compare the samples antioxidant activity. Lower $\mathrm{EC}_{50}$ values indicate higher For $\mathrm{ABTS}^{\bullet+}$ assays, liver pâtés $(5 \mathrm{~g})$ were mixed with $10 \mathrm{~mL}$ distilled water, stirred in a Vortex for 4 min and later in an Ultra-Turrax blender (Ika-Werke Gmbh \& Co.,Germany) at 11000 rpm during $10 \mathrm{~s}$. The mixture was filtrated through a Watman paper and the filtrate was immediately analyzed. A filtrate aliquot $(1 \mathrm{~mL})$ was dried in an oven at $40 \stackrel{\circ}{\mathrm{C}}$ overnight to calculate the dry matter content.

$\mathrm{ABTS}^{\bullet+}$ radical was chemically generated from $\mathrm{ABTS}-\mathrm{H}$ using manganese dioxide. ABTS ${ }^{\bullet+}$ scavenging activity was analyzed spectrophotometrically following the procedure described by Ramirez-Anguiano et al. (2007).

\section{Lipid oxidation measurement (TBARS value)}

Lipid oxidation in pâté with or without B. edulis (BC, BWF and BMF) supplementation was measured as thiobarbituric acid reactive substances (TBARS) using the TBA method of Pfalzgraf et al. (1995). This method is based on the malondialdehyde (MDA) reaction with 2-thiobarbituric acid (TBA) to 
176 obtain a pink pigment, resulting from the condensation of two molecules of TBA with one molecule of MDA (Sinnhuber et al. 1958). The substances that react with TBA are called TBA-reactive substances. TBARS value expressed as $\mu \mathrm{g}$ $\mathrm{MDA} / \mathrm{g}$ pâté and results were calculated in duplicate from a standard curve of TEP (1,1,3,3 tetraethoxypropane).

Briefly, pâté samples $(5 \mathrm{~g})$ were homogenized with $10 \mathrm{~mL}$ trichloroacetic acid $10 \%$ using the Ultra-Turrax (10 s, $11.000 \mathrm{rpm}$ ). The resulting mixtures were centrifuged at $5^{\circ} \mathrm{C}$ and $3500 \mathrm{rpm}$ during $20 \mathrm{~min}$ and supernatants were filtrated through a Watman paper. Afterwards, filtrates $(2 \mathrm{~mL})$ were mixed with $2 \mathrm{~mL}$ TBA $3 \mathrm{mmol} / \mathrm{L}$ and heated on a water bath at $100^{\circ} \mathrm{C}$ during $20 \mathrm{~min}$. When the samples cooled down absorbance at $531 \mathrm{~nm}$ was recorded.

\section{Antioxidants detection by TLC}

Compounds present in the water and methanol extracts obtained from $B$. edulis were separated and visualised using TLC silica sheets. Samples were developed and stained with a DPPH ${ }^{\bullet}$ solution as described in Soler-Rivas et al. (2000).

Organic antioxidants from $B$. edulis powder $(0.1 \mathrm{~g})$ were extracted using $1 \mathrm{~mL}$ methanol. The mixture was shaken and centrifuged at $14000 \mathrm{rpm}$ during 2 min. Drops $(10 \mu \mathrm{L})$ of the methanol extract and standard compounds were placed on the silica sheet and a TLC was developed using as mobile phase a mixture of toluene: ethyl acetate: formic acid (50:40:10) ( $/ \mathrm{v} / \mathrm{v})$. The TLC sheet was dried and stained with the $\mathrm{DPPH}^{\bullet}$ solution to detect only those compounds with antioxidant activity. 
200 Aqueous extracts were prepared as above described for methanol fractions but using water as solvent. Afterwards, they were submitted to filtration to separate small molecules from proteins and polysaccharides since the LMW fraction was mainly responsible for the high antioxidant activity as previously observed (Ramirez-Anguiano et al. 2007). Two hundred microliters of freshly prepared water extracts $(100 \mathrm{mg} / \mathrm{mL})$ were submitted to filtration using Microcom filters (Millipore) with a cut off of 10000 daltons and a microfuge (14000 rpm). Drops $(2 \mu \mathrm{L})$ of the $\mathrm{LMW}$ fraction and standard compounds were placed on silica sheet and TLC was developed using as mobile phase a mixture of methanol: formic acid: acetic acid: water (75:16:8:1) (v/v/v/v).

\section{Statistical analysis}

One way analysis of variance (ANOVA) was performed using a Statgraphics $\circledast$

Plus 3.1 for Windows software (Statistical Graphics Corporation, Maryland, USA). The mean comparison test used was Fisher's least significant differences procedure (LSD).

\section{RESULTS AND DISCUSSION}

\section{Effect of processing on radical scavenging activities}

Two steps are critical during a pâté processing because they might influence the antioxidant levels of a freshly prepared pâté. During mincing of the different ingredients, oxygen get into the mixture and lipid oxidations might take place. The second critical step is the heat treatment applied to the pâté in jars because increase of temperature implies increase of reaction velocity, and in iron-rich 
224 food matrices such as pâté, this metal might act as catalyst and accelerate lipid oxidation reactions.

When the domestic pâté recipe was followed, the minced paste was not left long enough to provoke a significant change in its antioxidants level (results not shown) but the heating process seemed detrimental (Table 1).

The thermal treatment applied to preserve the jars, following a traditional pâté recipe, reduced the antioxidant capacity of water soluble compounds of control pâtés since the $\mathrm{EC}_{50}$ of their $\mathrm{ABTS}^{\bullet+}$ scavenging capacity significantly increased after the heating. When the pâté was supplemented with complete $B$. edulis powder (BC), no significant reduction of water soluble antioxidants was observed. Moreover, in both paste and prepared pâté, the $\mathrm{EC}_{50}$ of supplemented preparations were significantly lower than the traditional control samples.

Heating did not significantly affect the methanol-soluble antioxidants present in the traditional pâté or in those supplemented with the mushroom powder (BC). However, the latter showed higher antioxidant properties since the $\mathrm{E}_{50}$ was, on average, $0.2 \mathrm{mg} / \mathrm{mL}$ while $1.1 \mathrm{mg} / \mathrm{mL}$ was established for traditional pâtés.

\section{Optimization of the $B$. edulis supplementation}

Pâté paste and mushroom powder $(\mathrm{BC})$ were mixed at several concentrations to design a functional product with a high antioxidant activity but also with adequate sensory properties and economically affordable. An excess of antioxidant compounds could lead to a pro-oxidant effect particularly on a high lipidic matrix such as liver pâté (Barlow 1990). 
248 Boletus edulis additions up to $7.5 \%(\mathrm{w} / \mathrm{w})$ increased the antioxidant capacity of the water soluble fraction of pâtés (Fig. 1a). The EC 50 of the traditional liver pâté (extrapolated by linear regression from the curves) changed from $0.46 \mathrm{mg} / \mathrm{mL}$ to $0.26 \mathrm{mg} / \mathrm{mL}$ by only $1 \% B$. edulis addition. Higher mushroom doses decreased furthermore the $\mathrm{EC}_{50}$ but up to certain extent. Increases of $5 \%$ and $7.5 \%$ mushroom powder did not significantly change the $\mathrm{EC}_{50}(0.15 \mathrm{mg} / \mathrm{mL})$.

Before measuring the antioxidant activity of the methanol soluble fractions in the above mentioned pâtés, two extraction methods were compared to detect a possible interference when organic solvents are utilized due to the high fat content of the samples. Nevertheless, no significant differences on the antioxidant activity were found between the methanol extracts submitted to the hexane pre-treatment to remove the fat and those without the washing step (Table 2). Results were also independent of the type of sample (control and supplemented) and apparently no synergistic effects occurred between the antioxidants present in the fatty matrix (soluble in organic solvents such as chloroform, hexane etc.) and those extracted with methanol. Therefore, the $\mathrm{DPPH}^{\bullet}$ scavenging capacity was evaluated without hexane pre-treatment. Boletus edulis addition to functionalize liver pâtés resulted in higher antioxidant activity of the methanol-soluble fraction with only $1 \%$ addition (Fig. $1 \mathrm{~b}$ ). The EC50 decreased almost half concentration, from 1.18 in control samples to 0.62 $\mathrm{mg} / \mathrm{mL}$ in supplemented samples (Table 2). As observed for water soluble antioxidants, the $\mathrm{EC}_{50}$ was decreasing with increasing mushroom concentration.

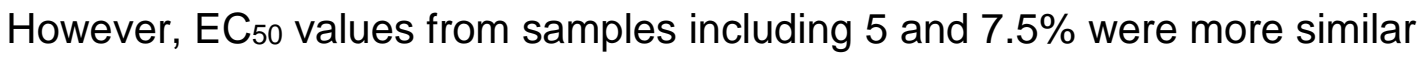
than between lower concentrations. 

edulis

Liver pâté pastes were also supplemented with two separate $B$. edulis fractions, a lyophilized fraction containing the water soluble compounds (BWF) and a dried methanol soluble fraction (BMF). Water extracted more compounds since $247.5 \pm 4.9 \mathrm{mg} / \mathrm{g} \mathrm{dw}$ were obtained compared to the $126.5 \pm 5.1 \mathrm{mg} / \mathrm{g}$ obtained using methanol. BWF fraction was added to pâté at 0.25 and $1.25 \%$ and BMF at 0.12 and $0.62 \%$ because those were the concentrations corresponding to $1 \%$ and $5 \%$ complete mushroom powder to compare the effect of the separate fractions with the complete fruiting body addition.

Control pâtés showed higher $\mathrm{EC}_{50}$ than in previous experiments (Table 3). These changes are usually due to the natural variability between samples preparations, particularly, liver and bacon pieces might differ from batch to batch. But, control and supplemented samples were prepared from the same pâté paste to allow further comparisons.

BWF additions ( 0.25 and $1.25 \%$ ) decreased respectively less than 13 and $30 \%$ the control EC 50 . However, samples including the complete mushroom powder (1 and $5 \% \mathrm{BC}$ ) decreased it respectively 43 and $67 \%$. BMF additions ( 0.12 and $0.62 \%)$ decreased respectively less than 10 and $58 \%$ the control $\mathrm{EC}_{50}$ while similar concentrations but including the complete mushroom powder ( 1 and $5 \%$ BC) decreased it respectively 47 and $78 \%$. Therefore, the use of a water or a methanol fraction instead of the complete mushroom as supplement to improve the antioxidant activity was less effective than the use of the complete fruiting body. Perhaps, synergic interactions between BC components might take place or some of the antioxidants were degraded during the extraction procedure. 
298 Thus, it is not encouraged the use of any separated mushroom extract to

299 functionalize liver pâtés.

\section{Effect of storage on antioxidant levels and lipid oxidation}

The effect of BC, BWF and BMF supplementation on pâté lipid oxidation was also studied (Fig. 2). No significant differences were observed between the

TBARs values of control samples and pâtés supplemented with both BWF concentrations and 1\% BC. These values were maintained constant during 15 storage days at $4^{\circ} \mathrm{C}$. The TBARs values of samples including BMF (both concentrations) or $5 \% \mathrm{BC}$ were slightly higher than control however only in those samples including BMF, the values increased after 15 days. Results were not surprising since BMF compounds were extracted with an organic solvent therefore, these compounds had a higher tendency to react with lipid-like compounds than water soluble extracts. Thus, these BMF extracts might have been partially oxidised during the extraction procedure or in case of $5 \% \mathrm{BC}$, they might have been added in excess. However, lipid oxidation levels were in all the samples very low and even lower than other pâtés functionalized with plants extracts (Estevez et al. 2007).

The antioxidant activity of the BWF and BMF supplemented pâtés were lower than those including the complete fruiting body and the methanol fractions slightly enhanced lipid oxidation thus, none of the separated mushroom extracts was further more utilized to functionalize liver pâtés and the complete $B$. edulis fruiting bodies were added but in concentrations lower than $5 \%(w / w)$. Then, control pâtés and pâtés supplemented with 2.5\% Boletus edulis powder were prepared and stored at room temperature for 60 days to study the lipid 
323 oxidation and the stability of the high antioxidant activity observed in supplemented samples (BC).

Water soluble antioxidants presents in control and supplemented samples were rather stable during 30 days because the $\mathrm{ABTS}^{\bullet+}$ scavenging capacity did not significantly changed in samples with 0,15 and 30 storage days (Fig. 3a). Control samples showed on average an $\mathrm{EC}_{50}$ of $0.3 \mathrm{mg} / \mathrm{mL}$ and supplemented samples maintained their higher antioxidant activity $\left(E_{50} 0.17 \mathrm{mg} / \mathrm{mL}\right.$ on average). Storage for 60 days provoked a decrease in the radical scavenging activities of both control and supplemented pâtés being the later still higher than the control.

Similarly, the antioxidant activity of the methanol soluble fraction extracted from both control and supplemented pâtés did not change within the 30 storage days (Fig. 3b). Afterwards, a high reduction was noticed after 60 days in control samples while supplemented pâtés showed only a low reduction in their DPPH scavenging capacity after those 60 days.

The lipid oxidation was concomitantly measured and no significant differences were observed from 0 up to 60 storage days in both control pâtés and samples supplemented with B. edulis powder (Fig. 3c). The latter samples showed a slightly higher TBARs values than the control although they were still very low indicating a proper stability of the lipid matrix during 60 days if Boletus edulis was applied at the selected concentration $(2.5 \% \mathrm{w} / \mathrm{w})$.

\section{Antioxidants separation by TLC}


346 Boletus methanol and water extracts were developed by TLC to separate and detect the type of compounds potentially responsible for the high antioxidant activity observed.

When the methanol extracts were developed, only 2 bands with antioxidant activity were observed (Fig. 4a). One band migrated $\left(R_{f}=0.86\right)$ and the other remained at the application point. The first band could be ergosterol or ergosterol derivatives since the band showed similar $\mathrm{R}_{\mathrm{f}}$ value than a commercially available ergosterol used as standard and their UV-spectra coincided when they were scratched from the silica sheet. Ergosterol is a common compound for fungi since it is a cell membrane component (BarajasAceves et al. 2002) and a vitamin $D_{2}$ precursor (Teichmann et al. 2007). It is also able to decrease lipid peroxidation and scavenge radicals (Zhang et al. 2002; Hu et al. 2006; Kobori et al. 2007). Moreover, the ergosterol concentration in this $B$. edulis strain was $7.73 \mathrm{mg} / \mathrm{g}$ and it was the major compound of the unsapponificable fraction (Ramirez-Anguiano, 2009). No ascorbic acid, $\alpha$-tocopherol, ergocalcipherol (vit. $\left.\mathrm{D}_{2}\right)$ (co-migrated with vit. $\left.D_{3}\right)$ and $\beta$-carotene $\left(R_{f}=1\right)$ were detected, apparently their contribution to the antioxidant activity of this fraction was insignificant. The vitamin $D_{2}$ levels in $B$. edulis were 1000 fold lower concentration than ergosterol (Mattila et al. 2002; Teichmann et al. 2007) and the highest concentration described for the other compounds were still 2-100 fold lower than ergosterol (Tsai et al. 2007; Jaworska and Bernas, 2009), thus their contribution might be below the detection level of the TLC-DPPH assay. However, the most intense band did not migrate indicating that the antioxidant activity was mostly due to very polar compounds which might be mainly soluble 
371 in water and partially in methanol. Therefore, the water extract was also analyzed by TLC.

The water extract was fractionated in a low molecular weight (LMW) and a high molecular weight (HMW) fractions and only the LMW fraction was applied to TLC sheets since the HMW contained antioxidant polysaccharides bound to proteins (Liu et al. 1997) but they contributed minimally to the high antioxidant activity observed in the complete water extract (Ramirez-Anguiano et al. 2007). The TLC development of the water extract yielded three bands (Fig. 4b), a fine band $\left(R_{f}=0.68\right)$ with very low intensity and two other more intense at the application point and at similar migration place than ergothioneine $\left(R_{f}=0.13\right)$.

L-Ergothioneine is water soluble thiol compound (2-thioimidazole betaine) with high antioxidant capacity (Dubost et al. 2007) present in high amounts in $B$. edulis fruiting bodies (528 mg/kg fw) (Ey et al. 2007) and the UV spectrum of the $B$. edulis band extracted from the silica sheet resembled ergotionethine (Dubost et al. 2006).

Other reports mentioned the presence of alkaloids, organic acids and unidentified phenols which could also be present in the applied LMW water fraction. Alkaloids could be partially extracted and with the utilized mobile phase they might migrate, perhaps they could be responsible of the fine band observed $\left(R_{f}=0.68\right)$. B. edulis contained oxalic, citric, malic, succinic and fumaric acids being malic acid the compound present in higher amount (Ribeiro et al. 2008). These compounds have not interesting antioxidant activities but they influence the $\mathrm{pH}$ and acid $\mathrm{pHs}$ shift the DPPH absorbance maximum producing false positives when compared with samples with neutral pHs. Therefore, they might influence the yellow spot visualized at the application 
point (because those compounds are not expected to migrate with the utilized mobile phase). However, phenolic compounds and peptides might also be present at the application point and might be involved in the observed antioxidant activity. The LMW fraction contained $36.68 \mathrm{mg} / \mathrm{g}$ phenolic compounds and $4.74 \mathrm{mg} / \mathrm{g}$ peptides (Ramirez-Anguiano, 2009). Thus, since most of the reports pointed the phenolic fraction as responsible of the antioxidant activity observed at the application point (Soares et al. 2009) and they were in high concentration in the LMW extracts they might be the major responsible compounds of the detected activity. Thus, the antioxidant activity of the water extracts might be mainly due to ergothioneine, and also probably due to the phenolic compounds.

Concluding, a functional liver pâté might be easily prepared by direct supplementation with only $1-2.5 \%$ of powdered $B$. edulis fruiting bodies. The antioxidant activity of supplemented pâtés was higher than traditional pâtés, it was maintained during the manufacture processes and pâté storage and did not induce lipid oxidation. The antioxidant activity of the methanol extract might be due to the ergosterol derivatives and polar compounds partially extracted from the water. The water extracts contained ergothioneine but also other still unidentified phenols. Further investigations are directed at the present to identify those compounds.

\section{ACKNOWLEDGMENTS}

University of Guadalajara (Jalisco, México) is acknowledged for the financial support granting to A.C. Ramirez-Anguiano with a doctoral fellowship. 
421 This work was also supported by the AGL2004-07227-C02-02 project from the

Ministerio de Ciencia y Tecnología under the framework of the $\mathrm{R}+\mathrm{D}+\mathrm{I}$ National

Program (2004-2007) and ALIBIRD-CM S-0505/AGR-0153 regional program from the Comunidad de Madrid, Spain.

BARAJAS-ACEVES, M., HASSAN, M., TINOCO, R. and VAZQUEZ-DUHALT, R. 2002. Effect of pollutants on the ergosterol content as indicador of fungal biomasa. J. Microbiol. Meth. 50, 227-236.

BARLOW, S.M. 1990. Toxicological aspects of antioxidants used as food additives. In: Food antioxidants Ed. HUDSON, B.J.F. Elsevier Applied Science. London and New York.

DUBOST, N.J., BEELMAN, R.B., PETERSON, D. and ROYSE, D.J. 2006. Identification and quantification of ergothioneine in cultivated mushrooms by liquid chromatography-mass spectroscopy. Int. J. Med. Mushrooms 8, 215-222.

DUBOST, N.J., OU, B. and BEELMAN, R.B. 2007. Quantification of polyphenols and ergothioneine in cultivated mushrooms and correlation to total antioxidant capacity. Food Chem. 105, 727-735.

ESTÉVEZ, M., RAMÍREZ, R., VENTANAS, S. and CAVA, R. 2007. Sage and rosemary essential oils versus BHT for the inhibition of lipid oxidative reactions in liver pâté. LWT - Food Sci. Technol. 40, 58-65.

EY, J., SCHÖMIG, E., and TAUBERT, D. 2007. Dietary sources and antioxidant effects of ergothioneine. J. Agric. Food Chem. 55, 6466-6474. 
FALANDYSZ, J. 2003. Selenium in selected species of mushrooms from Poland. Roczniki Panstwowego Zakladu Higieny 54, 249-254.

HU, S.H., LIANG, Z.C., CHIA, Y.C., LIEN, J.L., CHEN, K.S., LEE, M.Y. and WANG, J.C. 2006. Antihyperlipidemic and antioxidants effects of extracts from Pleurotus citrinopileatus. J. Agric. Food Chem. 54, 2103-2110.

JAWORSKA, G. and BERNAS, E. 2009. The effect of preliminary processing and period of storage on the quality of frozen Boletus edulis (Bull:Fr.) mushrooms. Food Chem. 113, 936-943.

KANNER, J., HAZAN, B. and DOLL, L. 1991. Catalytic 'free' iron ions in muscle foods. J. Agric. Food Chem. 36, 412-415.

KITZBERGER, C.S.G., SMÂNIA, A., CURI PEDROSA, R. and SALVADOR FERREIRA, S.R. 2007. Antioxidant and antimicrobial activities of shiitake (Lentinula edodes) extracts obtained by organic solvents and supercritical fluids. J. Food Eng. 80, 631-638.

KOBORI, M., YOSHIDA, M., OHNISHI-KAMEYAMA, M. and SHINMOTO, H. 2007. Ergosterol peroxide from an edible mushroom suppresses inflammatory responses in AW264.7 macrophages and growth of HT29 colon adenocarcinoma cells. Brit. J. Pharmacol. 150, 209-219.

LEE, S.J., YEO, W.H., YUN, B.S. and YOO, I.D. 1999. Isolation and sequence analysis of new peptaibol, boletusin, from Boletus spp. J. Pept. Sci. 5, 374378.

LIU, F., OOI, V.E.C. and CHANG, S.T. 1997. Free radical scavenging activities of mushroom polysaccharide extracts. Life Sci. 60, 763-771

MANZI, P., AGUZZI, A. and PIZZOFERRATO, L. 2001. Nutritional value of mushrooms widely consumed in Italy. Food Chem. 73, 321-325. 
MATTILA, P., KÖNKÖ, K., EUROLA, M., PIHLAVA, J.M., ASTOLA, J., VAHTERISTO, L., HIETANIEMI, V., KUMPULAINEN, J., VALTONEN, M. and PIIRONEN, V. 2001. Contents of vitamins, mineral elements and some phenolic compounds in cultivated mushrooms. J. Agric. Food Chem. 49, 2343-2348.

MATTILA, P., LAMPI, A.M., RONKAINEN, R., TOIVO, J. and PIIRONEN, V. 2002. Sterol and vitamin $D_{2}$ contents in some wild and cultivated mushrooms. Food Chem. 76, 293-298.

OUZOUNI, P.K. and RIGANAKOS, K.A. 2007. Nutricional value and metal content profile of Greek wild edible fungi. Acta Aliment. 36, 99-110.

PFALZGRAF, A., FRIGG, M. and STEINHART, H. 1995. $\alpha$-Tocopherol contents and lipid oxidation in pork muscle and adipose tissue during storage. J. Agric. Food Chem. 43, 1339-1342.

PINHO, O., FERREIRA, I.M.P.L.V.O., OLIVEIRA, M.B.P.P. and FERREIRA, M.A. 2000. Quantification of synthetic phenolic antioxidants in liver pâtés. Food Chem. 68, 353-357.

RAMIREZ-ANGUIANO, A.C., SANTOYO, S., REGLERO, G. and SOLERRIVAS, C. 2007. Radical scavenging activities, endogenous oxidative enzymes and total phenols in edible mushrooms commonly consumed in Europe. J. Sci. Food Agric. 87, 2272-2278.

RAMIREZ-ANGUIANO, A.C. 2009. Estudio de las propiedades funcionales de los hongos comestibles para el diseño de alimentos cárnicos funcionales. Department of Applied Chemistry-Physic. Faculty of Science. Universidad Autonoma de Madrid. Ph.D. thesis. 
RIBEIRO, B., LOPES, R., ANDRADE, P.B., SEABRA, R.M., GONÇALVES, R.F., BAPTISTA, P., QUELHAS, I. and VALENTÃO, P. 2008. Comparative study of phytochemicals and antioxidant potential of wild edible mushroom caps and stipes. Food Chem. 110, 47-56.

SANTOYO, S., RAMÍREZ-ANGUIANO, A.C., REGLERO, G. and SOLER-

RIVAS, C. 2009. Improvement of the antimicrobial activity of edible mushrooms extracts by inhibition of oxidative enzymes. Int. J. Food Sci. Technol. 44, 10571064.

SARIKURKCU, C., TEPE, B. and YAMAC, M. 2008. Evaluation of the antioxidant activity of four edible mushrooms from the Central Anatolia, Eskisehir - Turkey: Lactarius deterrimus, Suillus collitinus, Boletus edulis, Xerocomus chrysenteron. Bioresource Technol. 99, 6651-6655.

SINNHUBER, R.O., YU, I.C. and YU, T.C. 1958. Characterization of the red pigment formed in the 2-thiobarbituric acid determination of oxidative rancidity. Food Res. 23, 624-634.

SOLER-RIVAS, C., ESPÍN, J.C. and WICHERS, H.J. 2000. An easy and fast test to compare total free radical scavenger capacity of foodstuffs. Phytochem Anal 11, 330-338.

SOARES, A.A., GIATTI MARQUES DE SOUZA, C., DANIEL, F.M. PEZENTE FERRARI, G., GOMES DA COSTA, S.M. and PERALTA, R.M. 2009. Antioxidant activity and total phenolic content of Agaricus brasiliensis (Agaricus blazei Murril) in two stages of maturity. Food Chem. 112, 775781.

TEICHMANN, A., DUTTA, P.C., STAFFAS, A. and JÄGERSTAD, M. 2007. Sterol and vitamin D2 concentrations in cultivated and wild grown 
mushrooms: Effects of UV irradiation. LWT - Food Sci. Technol. 40, 815822. $42,1620-1624$ 
TABLE 1.

ABTS ${ }^{\bullet+}$ AND DPPH・ SCAVENGING ACTIVITIES OF WATER AND METHANOL EXTRACTS OBTAINED FROM PÂTÉS WITH AND WITHOUT 7.5\% B. EDULIS ADDITION BEFORE AND AFTER THE THERMAL TREATMENT.

\begin{tabular}{|l|c|c|c|c|}
\hline & \multicolumn{2}{|c|}{ EC 50 (ABTS) $\mathrm{mg} / \mathrm{mL}$} & \multicolumn{2}{c|}{ EC 50 (DPPH) mg/mL } \\
& (water soluble compounds) & After & Before & After \\
\hline Samples & Before & $0.46 \pm 0.02^{3}$ & $1.11 \pm 0.06^{\mathrm{a}}$ & $1.18 \pm 0.01^{\mathrm{a}}$ \\
\hline Control & $0.28 \pm 0.01^{1}$ & $0.15 \pm 0.02^{2}$ & $0.20 \pm 0.02^{\mathrm{b}}$ & $0.24 \pm 0.02^{\mathrm{b}}$ \\
\hline $7.5 \%$ B. edulis & $0.12 \pm 0.01^{2}$ & 0.1 soluble compounds) & \\
\hline
\end{tabular}

542 Values are the mean \pm SD of three separate experiments

${ }^{1,2,3}$ Denotes statistically significant differences $(P<0.05)$ among $E_{50(A B T S)}$ values a,bDenotes statistically significant differences $(P<0.05)$ among $\mathrm{EC}_{50(\mathrm{DPPH})}$ values 
TABLE 2.

DPPH• SCAVENGING ACTIVITIES OF METHANOL EXTRACTS OBTAINED FROM PÂTÉS SUPPLEMENTED WITH SEVERAL B. EDULIS CONCENTRATIONS WITH OR WITHOUT A HEXANE PRE-TREATMENT.

\begin{tabular}{|l|c|c|}
\hline & \multicolumn{2}{|c|}{ EC $50(\mathrm{DPPH}) \mathrm{mg} / \mathrm{mL}$} \\
\hline Samples & With hexane pretreatment & Direct methanol extraction \\
\hline Control & $1.20 \pm 0.01^{\mathrm{a}}$ & $1.18 \pm 0.01^{\mathrm{a}}$ \\
\hline $1 \%$ B. edulis & $0.59 \pm 0.04^{\mathrm{b}}$ & $0.62 \pm 0.02^{\mathrm{b}}$ \\
\hline $2.5 \%$ B. edulis & $0.30 \pm 0.01^{\mathrm{c}}$ & $0.34 \pm 0.03^{\mathrm{c}}$ \\
\hline $5 \%$ B. edulis & $0.26 \pm 0.01^{\mathrm{d}}$ & $0.26 \pm 0.01^{\mathrm{d}}$ \\
\hline $7.5 \%$ B. edulis & $0.21 \pm 0.01^{\mathrm{f}}$ & $0.23 \pm 0.01$ \\
\hline
\end{tabular}

Values are the mean \pm SD of three separate experiments a,b,c,d,e,f Denotes statistically significant differences $(\mathrm{P}<0.05)$ among $\mathrm{EC}_{50(\mathrm{DPPH})}$ values 
TABLE 3.

ABTS •+ SCAVENGING ACTIVITIES OF WATER EXTRACTS OBTAINED

FROM PÂTÉS SUPPLEMENTED WITH B. EDULIS AQUEOUS FRACTIONS

(BWF) AND DPPH• SCAVENGING ACTIVITIES OF METHANOL EXTRACTS OBTAINED FROM PÂTÉS SUPPLEMENTED WITH B. EDULIS METHANOL FRACTIONS (BMF).

\begin{tabular}{|c|c|c|c|}
\hline $\begin{array}{c}\text { Aqueous fraction } \\
(\mathrm{BWF})\end{array}$ & $\begin{array}{c}\text { EC } 50(\mathrm{ABTS}) \\
(\mathrm{mg} / \mathrm{mL})\end{array}$ & $\begin{array}{c}\text { Methanol fraction } \\
(\mathrm{BMF})\end{array}$ & $\begin{array}{c}\mathrm{EC}_{50}(\mathrm{DPPH}) \\
(\mathrm{mg} / \mathrm{mL})\end{array}$ \\
\hline 0 & $1.03 \pm 0.01^{1}$ & 0 & $1.4 \pm 0.02^{\mathrm{a}}$ \\
\hline 0.25 & $0.90 \pm 0.00^{2}$ & 0.12 & $1.27 \pm 0.01^{\mathrm{b}}$ \\
\hline 1.25 & $0.73 \pm 0.01^{3}$ & 0.62 & $0.59 \pm 0.00^{\mathrm{c}}$ \\
\hline
\end{tabular}
a,b,c Denotes statistically significant differences $(\mathrm{P}<0.05)$ among $\mathrm{EC}_{50(\mathrm{DPPH}) \text { values }}$ 
FIG. 1. A) ABTS •+ SCAVENGING CAPACITY OF WATER EXTRACTS AND B)

DPPH• SCAVENGING CAPACITY OF METHANOL EXTRACTS OBTAINED

FROM LIVER PÂTÉS CONTAINING DIFFERENT B. EDULIS

CONCENTRATIONS.

( $\square$ ) Control pâté,

(A) $1 \%$

$2.5 \%$

(•) $5 \%$ and

(घ) $7.5 \%$ mushroom addition.

FIG. 2. TBARS VALUES FROM CONTROL PÂTÉS AND PÂTÉS

SUPPLEMENTED WITH B. EDULIS AQUEOUS FRACTIONS (BWF), WITH $B$. EDULIS METHANOL FRACTIONS (BMF) AND WITH 1 AND 5\% OF COMPLETE MUSHROOM. "DENOTES STATISTICALLY SIGNIFICANT DIFFERENCES $(P<0.05)$ BETWEEN SAMPLES INCUBATED 0 AND 15 DAYS

FIG. 3. EVOLUTION DURING THE STORAGE TIME OF A) EC50(ABTS) OF WATER EXTRACTS, B) EC50(DPPH) OF METHANOL EXTRACTS AND C) TBARS VALUES OBTAINED FROM LIVER PÂTÉS WITH AND WITHOUT 2.5\% B. EDULIS SUPPLEMENTATION. "DENOTES STATISTICALLY SIGNIFICANT DIFFERENCES $(\mathrm{P}<0.05)$ BETWEEN CONTROL AND SUPLEMENTED SAMPLES

FIG. 4. A) METHANOL EXTRACT AND B) LMW FRACTION FROM THE WATER EXTRACT OBTAINED FROM BOLETUS EDULIS DEVELOPED BY TLC AND STAINED WITH A DPPH・SOLUTION.

$\mathrm{BE}=\mathrm{B}$. edulis extracts, $\mathrm{ERT}=$ ergothionenine, $\mathrm{ERG}=$ ergosterol, $\mathrm{ASC}=$ ascorbic acid, $\mathrm{TOC}=$ tocopherol, VitD3= Vitamin $\mathrm{D}_{3}$. 
600

601 
602 FIG. 1.

603 a)

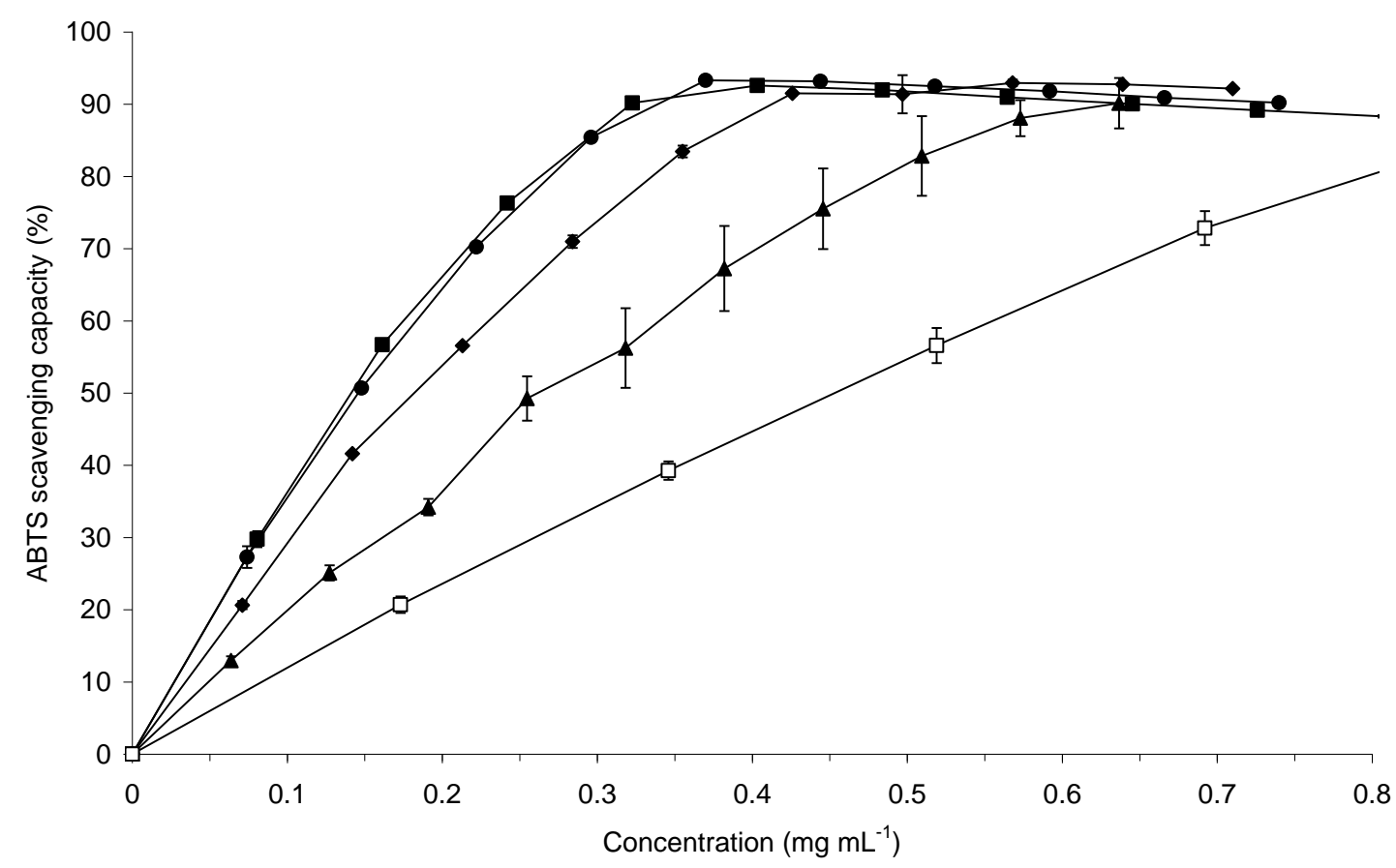

604

b)

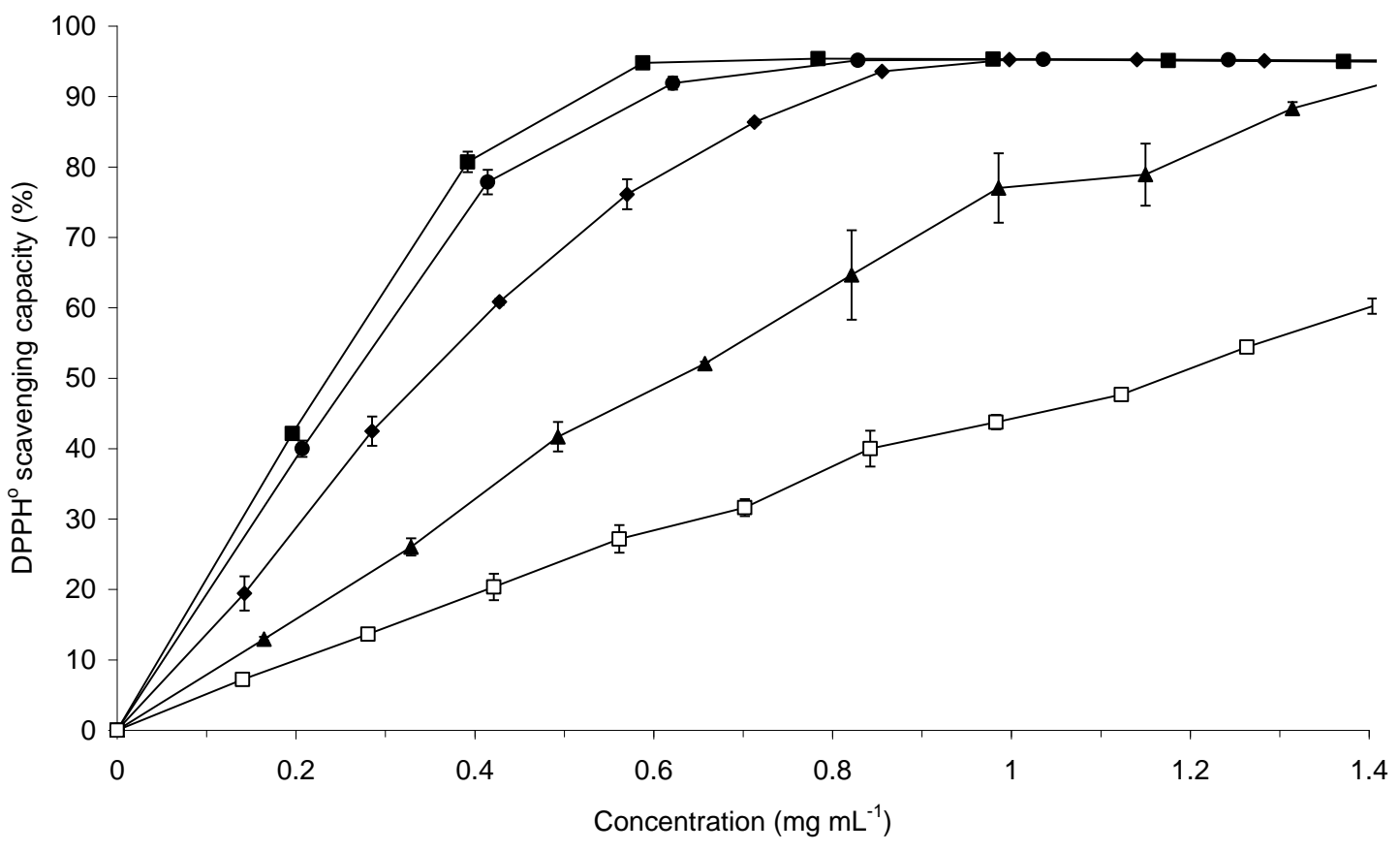

606

607 
FIG. 2.

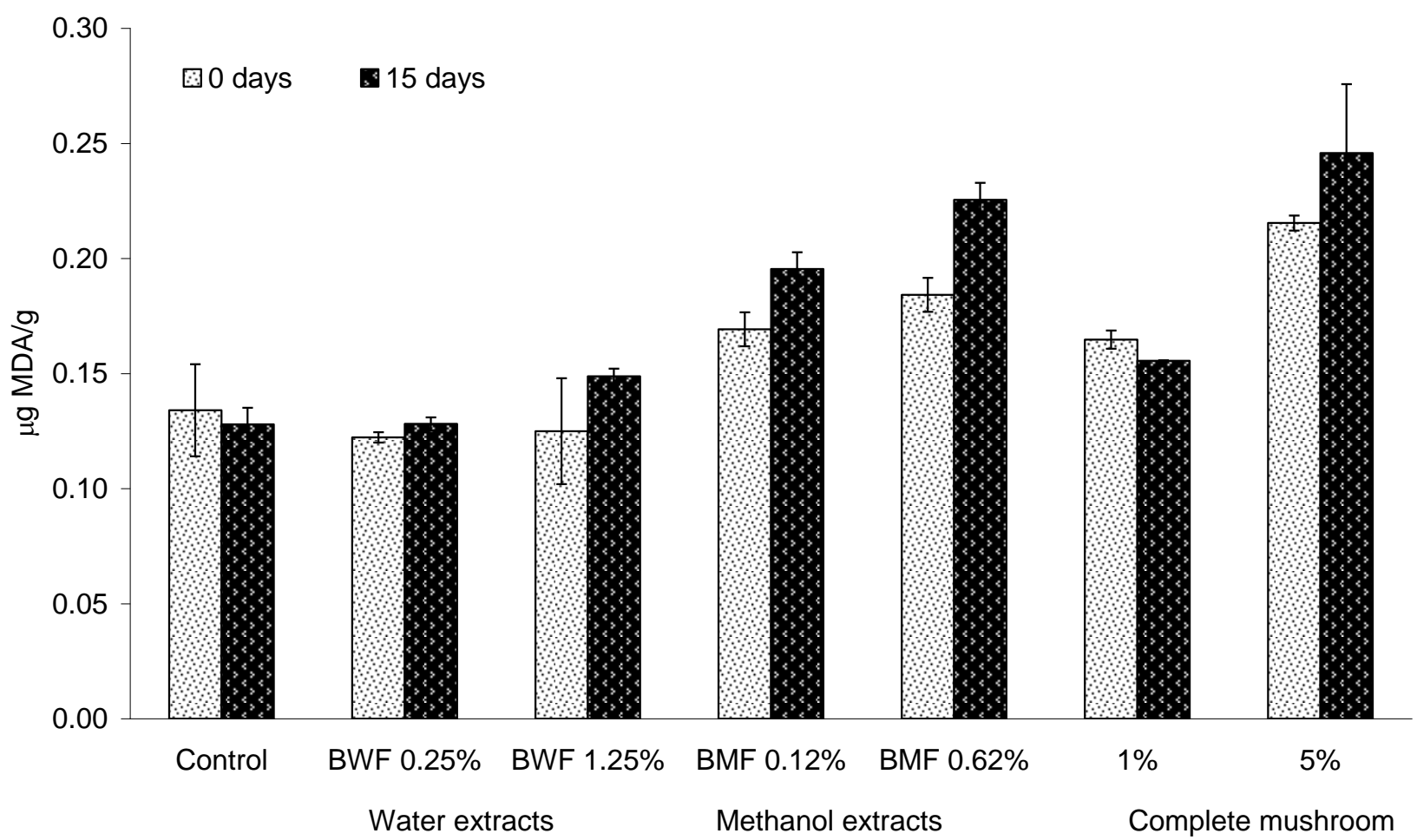

609 
FIG. 3.

a)

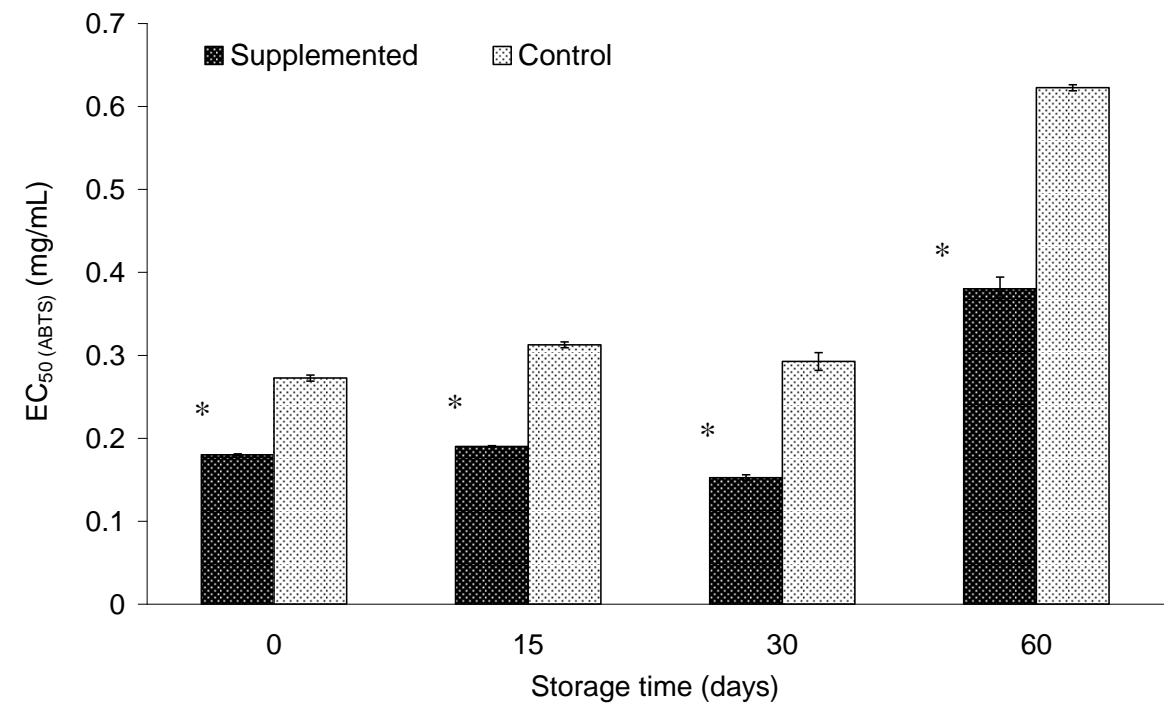

611

b)

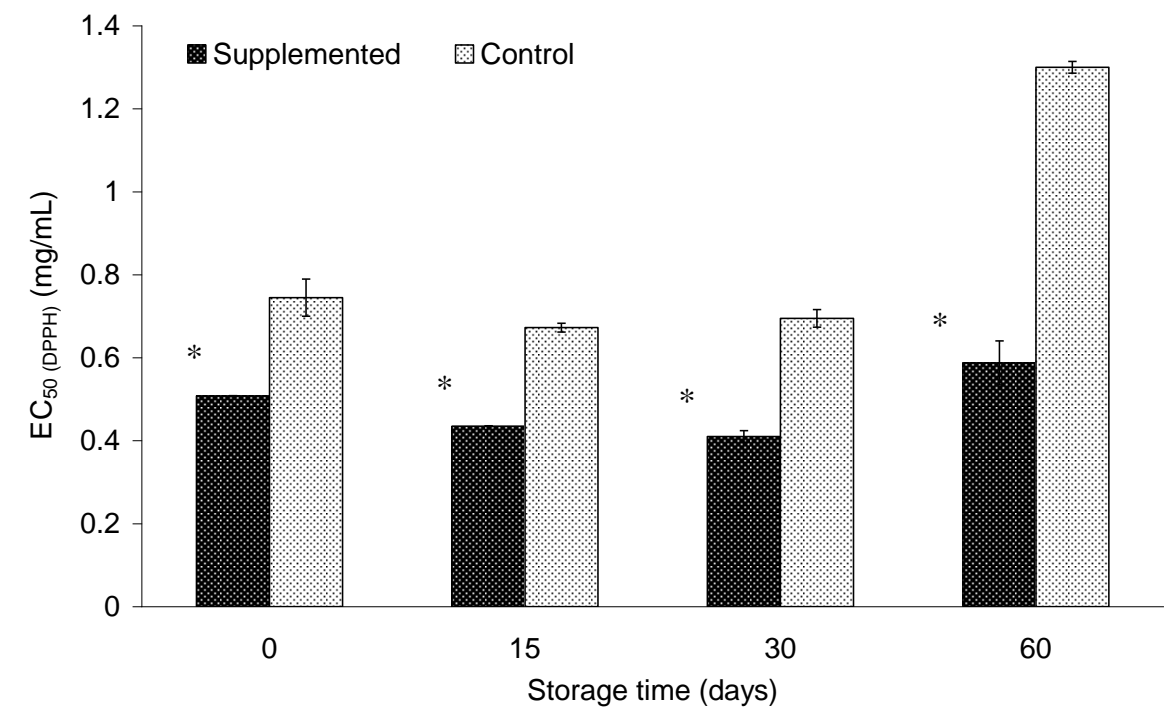

612

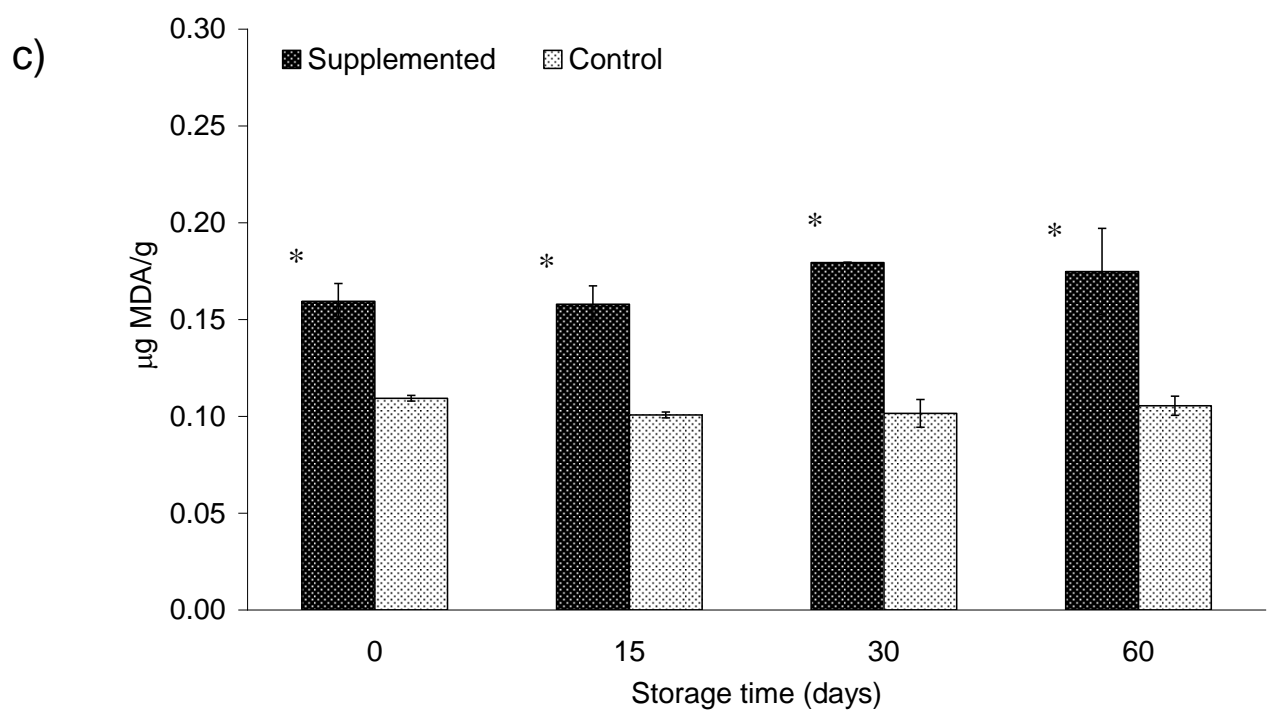


614 FIG. 4.

615

$616 \quad$ a)

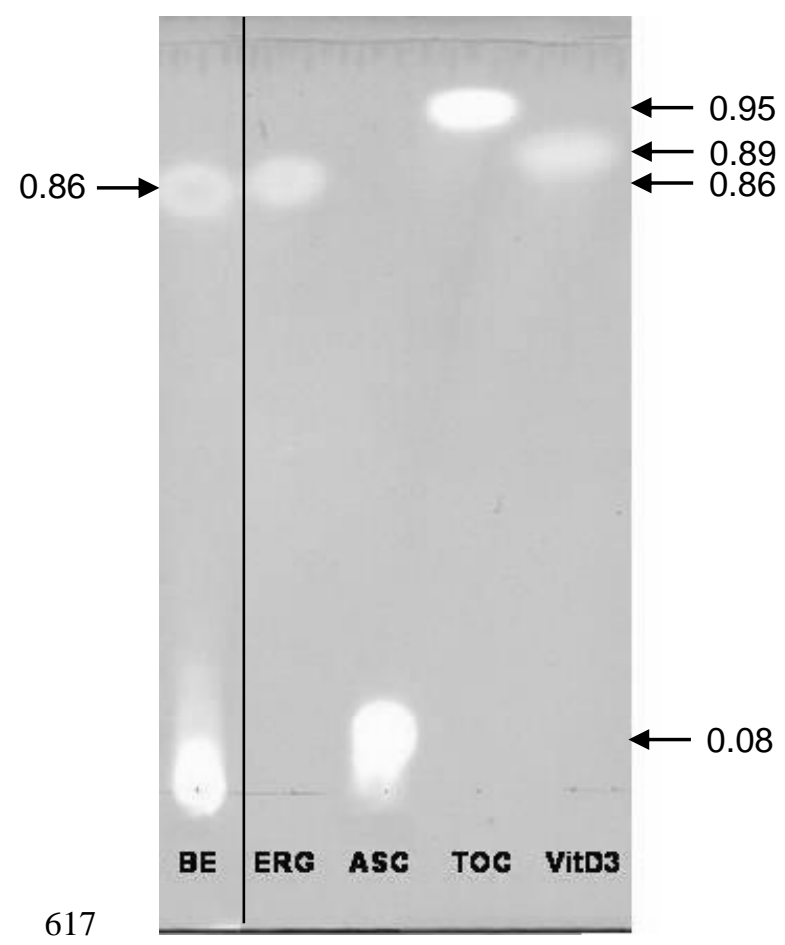

618

619 b)

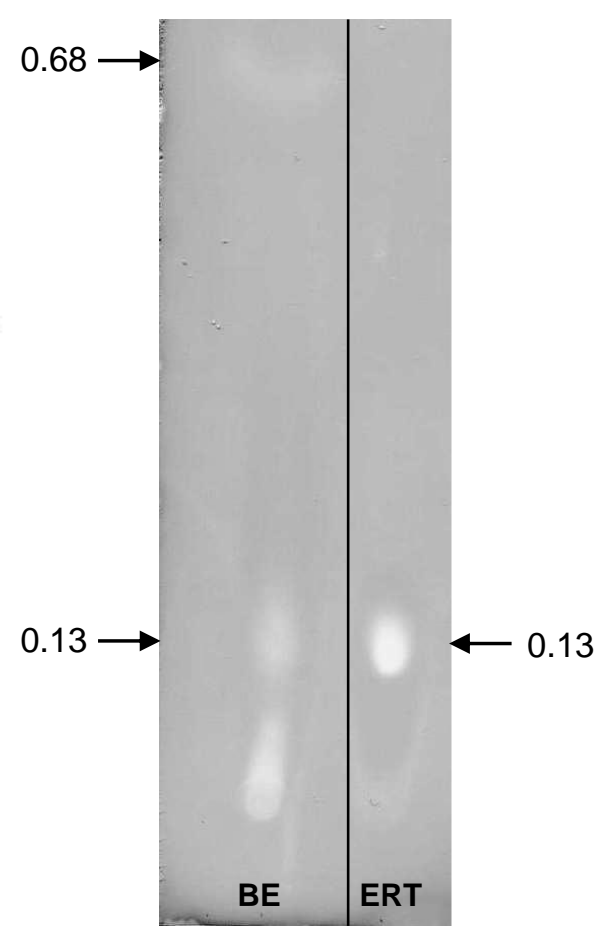

